\title{
Assessment of Conventional Autonomic Function Tests in Patients with Acute Intermittent Porphyria
}

\author{
Ankur ${ }^{1, *}$, Rampure Mahadevappa Dilip ${ }^{2}$, Irshad Hussain Askari ${ }^{3}$
}

\section{Ankur ${ }^{1, *}$, Rampure M Dil-} ip $^{2}$, Irshad Hussain Askari ${ }^{3}$

'Department of Physiology, MNR Medical College and Hospital, Sangareddy, Telangana, INDIA.

2Department of Medicine, Mahaveer Institute of Medical Sciences, Vikarabad, Telangana, INDIA.

${ }^{3}$ Department of Physiology, MNR Medical College and Hospital, Sangareddy, Telangana, INDIA.

\section{*Correspondence}

Dr. Ankur M.B.B.S, M.D

Physiology, Associate Professor, Department of Physiology. MNR Medical College and Hospital, Sangareddy-502294, Telangana, INDIA.

Phone: +91-8106983131

Email: ankurwadhwa.dr@gmail.com

\section{History}

- Submission Date: 17-08-2019

- Review completed: 20-10-2019;

- Accepted Date: 04-11-2019.

DOI : 10.5530/ijcep.2019.6.4.32

\section{Copyright}

(C) 2019 Phcog.Net. This is an openaccess article distributed under the terms of the Creative Commons Attribution 4.0 International license.

\begin{abstract}
Background and Aim: To assess the autonomic nerve functions in latent and manifest patients of acute intermittent porphyria. The aim of the present study was to study cardiovascular responses to autonomic nerve functions in patients of acute intermittent porphyria, we also tried to find out the relative sensitivity of the various tests employed to study cardiac dysautonomia in these cases. Methods: The study was carried out on thirty cases of acute intermittent porphyria to assess the cardiovascular reflexes. Twenty five healthy subjects closely matched for age and sex served as control. The cases were diagnosed by modified Watson Schwartz test, the cases of acute intermittent porphyria were divided into three groups. Results: The values of different autonomic nerve function tests were compared with control group and among the different groups of patients. The results were complied, compared and a conclusion was drawn. Immediate heart rate response to standing is more sensitive test than the Valsalva maneuver. Immediate heart rate response to standing is more sensitive and quite reliable which can easily be performed at bed side or even in outpatient departments, the test is simple and non-invasive. In our opinion, the test, beat to beat variation of heart rate to single deep breath is though easy to perform and more understandable, but lacks the sensitivity of other two tests. Conclusion: Significant cardiac dysautonomia is present in asymptomatic group, it is more marked in acute attack group. Immediate heart rate response to standing could be a more sensitive and reliable test in this dysfunction.

Key words: Acute intermittent porphyria, Autonomic nerve functions, Cardiac dysautonomia, Valsalva maneuver, Heart rate response to standing.
\end{abstract}

\section{INTRODUCTION}

Acute intermittent porphyria is an inborn error of metabolism characterised clinically by attacks of gastrointestinal and neurological dysfunction. The most important and usually the presenting complaint is pain abdomen, around umbilicus with minimum tenderness and without rebound tenderness, frequently associated with constipation and very occasionally with diarrhoea. As regards neurological dysfunction, the disease presents with complex manifestations involving central and peripheral nervous system including autonomic nervous system. ${ }^{[1]}$

Most of the common manifestations of acute intermittent porphyria are supposed to be due to involvement of autonomic nervous system. ${ }^{[2]}$ The cardiovascular manifestations of autonomic neuropathy of the disease are tachycardia, hypertension and postural hypotension. ${ }^{[3]}$

The neurological involvement makes the prognosis of the disease less favourable and the major cause of mortality of the disease is autonomic instability. [4] The cardiac autonomic neuropathy is probably the most sensitive index for neuronal damage in porphyria. ${ }^{[5]}$ Since very little work has been done on this aspect so far, this prompted to study cardiovascular

responses to autonomic nerve functions in this disease for a better understanding of this prognosis and treatment.

Persistence of neurological involvement in this form of peripheral neuropathy in some of the patients of porphyria as detected by Sorensen ${ }^{[6]}$ leads us to study cardiovascular responses in asymptomatic patients of porphyria also. The autonomic nerve function tests used in the present project to study the cardiovascular responses in acute intermittent porphyria are:

Valsalva manoeuvre, immediate heart rate response to standing and beat to beat variation of heart rate to single deep breath. The aim of this study was to study the autonomic nerve functions especially cardiovascular responses to the above mentioned tests in patients of acute intermittent porphyria. We also tried to find out the relative sensitivity of the various tests employed to study cardiac dysautonomia in these cases.

\section{MATERIALS AND METHODS}

The study was carried out on 30 cases of acute intermittent porphyria to assess the cardiovascular reflex-

Cite this article: Ankur, Dilip RM, Askari IH. Assessment of Conventional Autonomic Function Tests in Patients with Acute Intermittent Porphyria. Int J Clin Exp Physiol. 2019;6(4):118-21. 
es, admitted in medicine ward of Mamata Hospital, Khammam. Twenty five healthy subjects closely matched for age and sex served as controls. The patients with known evidence of cardiac disease, hypertension (other than due to porphyria), respiratory disease or thyrotoxicosis were excluded from the study. Diseases known to affect autonomic nerves except porphyria, such as diabetes mellitus, leprosy were excluded from the present study by relevant investigations. The patients known to have been taking drugs acting on autonomic nervous system and or cardiovascular system were also excluded from the study. A detailed history was taken and a thorough clinical examination with particular emphasis on neurological examination was carried out in each case. The cases were diagnosed by modified Watson Schwartz test. ${ }^{[7-10]}$

The cases of acute intermittent porphyria were divided into three groups

(a) Asymptomatic group: those who never had acute attack through excreting increased quantity of porphobilinogen in their urine.

(b) Remission group: those patients who at the time of observation were symptom free but had history of acute attacks in the past

(c) Acute attack group: those patients who presented in acute attack. For clinical evidence of autonomic neuropathy patients were investigated regarding history of diarrhoea, sweating disturbances, bladder dysfunction, upper gastrointestinal disturbances such as delayed emptying of stomach, palpitation, postural hypotension and impotence.

The following investigations were carried out in each case: urine examination, urine for porphobilinogen by modified Watson Schwartz test, blood examination, ECG and Valsalva maneuver ${ }^{[11]}$ Immediate heart rate response to standing, ${ }^{[12]}$ Beat to beat variation of heart rate to single deep breath. ${ }^{[13,14]}$ The study was approved by human ethical committee of Mamata Medical College and Hospital Khammam, Telangana, as well as the selected cases were first explained the purpose of this study and the willing cases had been included in the study before any further proceedings was done.

\section{Statistical Analysis of Data}

The data was expressed as Mean \pm SD. Statistical analysis was done using SPSS software, Version 17. Data between the groups were compared and analysed by unpaired $t$ test. One-way Analysis of Variance (ANOVA) was used to compare that data across the groups. $\mathrm{P}<0.05$ is considered as significant.

\section{RESULTS}

The present study was carried out on 30 established cases of acute intermittent porphyria. 25 normal healthy subjects, closely matched for age and sex served as controls.

In control group there were $12(48 \%)$ males and $13(52 \%)$ females, whereas the porphyria group included 18 (60\%) males and $12(40 \%)$ females. Maximum numbers of cases were in third decade both in control (12 subjects, $48 \%$ ) and porphyria group (13 subjects, $43.3 \%$ ).

The patients of acute intermittent porphyria were divided into three groups. In this study 7 patients belonged to acute attack group (4 males and 3 females), 12 to remission group ( 7 males and 5 females) and 11 to asymptomatic group (7 males 4 females).

\section{DISCUSSION}

In the present study, the mean Valsalva ratio in 25 control subjects was $1.56 \pm 0.30$ which is in accordance with the findings of other worker. ${ }^{[15]}$ The mean Valsalva ratio in 30 patients of acute intermittent porphyria was $1.29 \pm 0.20$. While comparing the values of mean Valsalva ratio between patients of acute intermittent porphyria and control group, we observed that cardiovascular response to Valsalva maneuver was abnor- mal and significant statistically $(P<0.01)$ Table 1 , indicating thereby that significant cardiac dysautonomia is present in cases of acute intermittent porphyria. Comparison between asymptomatic and control groups also showed that the cardiovascular response to this maneuver was abnormal and significant statistically $(P<0.01)$. The same was true when acute attack group $(P<0.01)$ and remission group $(P<0.01)$ were compared with control group Table1. This shows that abnormal cardiovascular response to Valsalva maneuver is present in all the three groups of acute intermittent porphyria, studied in the present study.

It is really surprising that cardiac dysautonomia was found to be present even in asymptomatic group. The nerve conduction velocity of the slow fibres of peripheral nerve as measured by Mustajoki $\mathrm{P}^{[16]}$ in individuals with latent porphyria has been reported as being slow, suggesting that a latent myelinopathic neuropathy may exist even in latent porphyria. Similarly, cardiac dysautonomia might also be one of the significant findings in asymptomatic group of acute intermittent porphyria. Presence of cardiac dysautonomia in practically all patients of acute attack group of acute intermittent porphyria shows that involvement of autonomic nervous system is quite common in this disease.

When different groups of acute intermittent porphyria were compared with each other, the cardiovascular response was found to be abnormal at $10 \%$ level $(P<0.1)$ between patients of asymptomatic and acute attack group and at $5 \%$ level $(P<0.05)$ between patients of remission group and acute attack group. No significant difference was observed when asymptomatic patients were compared with remission group $(P>0.1)$ Table 2.

Table 2 reveals that $t$ value is increasing progressively in asymptomatic, remission and acute attack groups in that order and the abnormal cardiac response is significantly more in acute attack as compared to that of asymptomatic and remission groups Table 2 . It is therefore, evident that cardiac autonomic nerve functions deteriorate progressively as the activity of disease increases.

In the present study the mean ratio of heart rate at $15^{\text {th }}$ and $30^{\text {th }}$ beat after standing in control group was $1.262 \pm 0.085 .{ }^{[17]}$ The mean value of the ratio in patients of porphyria was found to be $1.107 \pm 0.097$ which is very much low in comparison to the values of control group and found to be highly significant statistically $(P<0.001)$ Table 3.

From Table 3 it is quite evident that abnormal cardiovascular response to this test was present and was found to be statistically significant in all the groups of acute intermittent porphyria i.e. in asymptomatic $(P<0.01)$ remission $(P<0.001)$ and acute attack $(P<0.001)$ group. Presence of statistically significant cardiac dysautonomia with a progressive deterioration has been observed in all the three groups, by this test also.

When different groups of porphyria were compared with each other significant abnormal cardiovascular response was found to be present between patients of asymptomatic and acute attack groups $(P<0.05)$. Same was found true when remission group was compared to acute attack group $(P<0.01)$ Table 4 . This favours the statement given earlier that cardiac autonomic nerve functions deteriorate progressively as the activity of disease increases.

The difference of mean heart rate between minimum and maximum R-R interval during this test in control and porphyria group was $25.0 \pm 13.54$ and $20.0 \pm 12.3$ respectively. There was no significant difference between values of this test in control group and patient group $(P>0.1)$ Table 5, or in any of the groups of porphyria $(P>0.1)$ when compared, Table 6 suggesting that cardiac autonomic nerve functions are not much deteriorated as detected by this test. This is probably because of less sensitivity of this test, in detecting cardiac dysautonomia.

The mean values of these tests which are lower than the normal (mean-1 S.D.) were considered to be suggestive of presence of cardiac autonomic neuropathy in patients of acute intermittent porphyria. When this cri- 
Table 1: Comparison of Valsalva ratio between control group and different group of patients.

$\begin{array}{ccccc} & \begin{array}{c}\text { No. of } \\ \text { cases }\end{array} & \text { Mean } & \text { S.D } & \text { P } \\ \text { Control } & 25 & 1.56 & 0.30 & \\ \text { T.P } & 30 & 1.29 & 0.20 & <0.01 \\ \text { Control } & 25 & 1.56 & 0.30 & \\ \text { A.G } & 11 & 1.30 & 0.14 & <0.01 \\ \text { Control } & 25 & 1.56 & 0.30 & \\ \text { R.G } & 12 & 1.35 & 0.20 & <0.01 \\ \text { Control } & 25 & 1.56 & 0.30 & \\ \text { A.A.G } & 07 & 1.18 & 0.16 & <0.01\end{array}$

T.P $=$ Total patients, A.G = Asymptomatic group, R.G $=$ Remission group, A.A.G = Acute attack group.

Table 2: Comparison of Valsalva ratio among different groups of patients of acute intermittent porphyria.

\begin{tabular}{|ccccc} 
& $\begin{array}{c}\text { No. of } \\
\text { cases }\end{array}$ & Mean & S.D & P \\
\hline A.G & 11 & 1.30 & 0.14 & \\
R.G & 12 & 1.35 & 0.20 & $>0.1$ \\
A.G & 11 & 1.30 & 0.14 & \\
A.A.G & 07 & 1.18 & 0.16 & $<0.1$ \\
R.G & 12 & 1.35 & 0.20 & \\
A.A.G & 07 & 1.18 & 0.16 & $<0.05$ \\
\hline
\end{tabular}

A.G $=$ Asymptomatic group, R.G = Remission group, A.A.G $=$ Acute attack group.

Table 3: Comparison of immediate heart rate response to standing between control group and different group of patients.

\begin{tabular}{|ccccc|}
\hline & $\begin{array}{c}\text { No. of } \\
\text { cases }\end{array}$ & Mean & S.D & P \\
\hline Control & 25 & 1.262 & 0.085 & \\
T.P & 30 & 1.107 & 0.097 & $<0.001$ \\
Control & 25 & 1.262 & 0.085 & \\
A.G & 11 & 1.133 & 0.138 & $<0.01$ \\
Control & 25 & 1.262 & 0.085 & \\
R.G & 12 & 1.120 & 0.055 & $<0.001$ \\
Control & 25 & 1.262 & 0.085 & \\
A.A.G & 07 & 1.041 & 0.057 & $<0.001$ \\
\hline
\end{tabular}

T.P = Total patients, A.G = Asymptomatic group, R.G = Remission group, A.A.G $=$ Acute attack group.

teria was applied to the Valsalva maneuver, cardiac dysautonomia was present in 16 (53.33\%) cases of acute intermittent porphyria. The highest incidence was seen in acute attack group, $5(71.43 \%)$ cases. It was present in $6(50.0 \%)$ cases of remission group and in $5(45.45 \%)$ cases of asymptomatic group.
Table 4: Comparison of values of immediate heart rate response to standing in different groups of acute intermittent porphyria.

\begin{tabular}{ccccc} 
& $\begin{array}{c}\text { No. of } \\
\text { cases }\end{array}$ & Mean & S.D & P \\
\hline A.G & 11 & 1.133 & 0.138 & \\
R.G & 12 & 1.120 & 0.055 & $>0.1$ \\
A.G & 11 & 1.133 & 0.138 & \\
A.A.G & 07 & 1.041 & 0.057 & $<0.05$ \\
R.G & 12 & 1.120 & 0.055 & \\
A.A.G & 07 & 1.041 & 0.057 & $<0.01$ \\
\hline
\end{tabular}

A.G $=$ Asymptomatic group, R.G $=$ Remission group, A.A.G $=$ Acute attack group.

Table 5: Comparison of values of beat to beat variation of heart rate to single deep breath between control group and different groups of acute intermittent porphyria.

\begin{tabular}{|ccccc|} 
& $\begin{array}{c}\text { No. of } \\
\text { cases }\end{array}$ & Mean & S.D & P \\
\hline Control & 25 & 25.0 & 13.52 & \\
T.P & 30 & 20.0 & 12.30 & $>0.1$ \\
Control & 25 & 25.0 & 13.52 & \\
A.G & 11 & 20.0 & 12.05 & $>0.1$ \\
Control & 25 & 25.0 & 13.52 & \\
R.G & 12 & 18.0 & 12.08 & $>0.1$ \\
Control & 25 & 25.0 & 13.52 & \\
A.A.G & 07 & 23.0 & 12.43 & $>0.1$ \\
\hline
\end{tabular}

T.P $=$ Total patients, A.G = Asymptomatic group, R.G = Remission group, A.A.G $=$ Acute attack group.

Table 6: Comparison of values of beat to beat variation of heart rate to single deep breath among different groups of acute intermittent porphyria.

\begin{tabular}{ccccc} 
& $\begin{array}{c}\text { No. of } \\
\text { cases }\end{array}$ & Mean & S.D & P \\
\hline A.G & 11 & 20.0 & 12.05 & \\
R.G & 12 & 18.0 & 12.08 & $>0.1$ \\
A.G & 11 & 20.0 & 12.05 & \\
A.A.G & 07 & 23.0 & 12.43 & $>0.1$ \\
R.G & 12 & 18.0 & 12.08 & \\
A.A.G & 07 & 23.0 & 12.43 & $>0.1$ \\
\hline
\end{tabular}

A.G $=$ Asymptomatic group, R.G = Remission group, A.A.G = Acute attack group.

The cardiac dysautonomia, as detected by immediate heart rate response to standing, was present in $25(83.33 \%)$ cases of acute intermittent porphyria. Out of these 25 cases, cardiac dysautonomia was detected in all the $7(100.00 \%)$ cases of acute attack, in $10(83.33 \%)$ cases of remission and $8(72.72 \%)$ cases of asymptomatic group. 
Table 7: Showing the incidence of autonomic neuropathy in different groups of acute intermittent porphyria.

\begin{tabular}{|c|c|c|c|c|}
\hline \multirow{2}{*}{\multicolumn{2}{|c|}{ 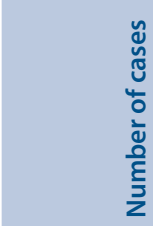 }} & \multicolumn{3}{|c|}{ Number of cases having autonomic neuropathy. } \\
\hline & & $\begin{array}{l}\text { Valsalva } \\
\text { maneuver }\end{array}$ & $\begin{array}{l}\text { Immediate heart } \\
\text { rate response to } \\
\text { standing }\end{array}$ & $\begin{array}{l}\text { Heart rate to } \\
\text { single deep } \\
\text { breath }\end{array}$ \\
\hline A.G & 11 & $5(45.45 \%)$ & $8(72.72 \%)$ & $1(9.09 \%)$ \\
\hline R.G & 12 & $6(50.00 \%)$ & $10(83.3 \%)$ & $7(58.33 \%)$ \\
\hline A.A.G & 07 & $5(71.43 \%)$ & $7(100.0 \%)$ & $2(28.55 \%)$ \\
\hline T.P & 30 & $16(53.3 \%)$ & $25(83.3 \%)$ & $10(33.33 \%)$ \\
\hline
\end{tabular}

A.G $=$ Asymptomatic group, R.G $=$ Remission group, A.A.G $=$ Acute attack group, T.P = Total patients

Abnormal cardiovascular response as detected by the test, beat to beat variation of heart rate to single deep breath was found in 10 (33.33\%) cases of acute intermittent porphyria. Out of these ten cases, 2 (28.55\%) cases were from acute attack group, 7 (58.33\%) from remission group and $1(9.09 \%)$ from asymptomatic group Table 7.

From the present study it is quite evident that the test, immediate heart rate response to standing is more sensitive than the test Valsalva maneuver. The test beat to beat variation of heart rate to single deep breath is very much less sensitive as compared to the other two tests. ${ }^{[12,18,19]}$

\section{CONCLUSION}

The autonomic neuropathy is seen in patients of acute intermittent porphyria. Though significant cardiac dysautonomia is present in asymptomatic group, it is more marked in acute attack group. Although Valsalva maneuver has been observed to be a reliable and more sensitive test by other workers but we have observed that the test, immediate heart rate response to standing is more sensitive and quite reliable which can easily be performed at bed side or even in outpatient departments. The test is simple and non - invasive. In our opinion, the test, beat to beat variation of heart rate to single deep breath is though easy to perform and more understandable, but lacks the sensitivity of other two tests.

\section{ACKNOWLEDGEMENT}

Nil.

\section{CONFLICT OF INTEREST}

The authors declare no conflict of interest.

\section{ABBREVIATIONS}

TP: Total patients; AG: Asymptomatic group; RG: Remission group;

AAG: Acute attack group.

\section{REFERENCES}

1. Tschudy DP, Valsamis M, Magnussen CR. Acute intermittent porphyria: Clinical and selected research aspects. Ann Intern Med. 1975;83(6):851-64.

2. Goldberg A. Acute intermittent porphyria: A study of 50 cases. QJM: Int J Med 1959;28(2):183-209

3. Henry T, Vikram PK, Pashtoon MK. Clinical Manifestations and Diagnostic Challenges in Acute Porphyrias. Case Rep Hematol. 2013;1-6.

4. Mehta RS, Pandey GN. Peripheral neuropathy in acute intermittent prophyria. Neurol India. 1965;13(4):192-5

5. Pischik E, Kauppinen R. Neurological manifestations of acute intermittent porphyria. Cell Mol Biol. 2009;55(1):72-83.

6. Sorensen AW, With TK. Persistent pareses after porphyric attacks. S Afr Med J. 1971;25:101-3.

7. Watson CJ, Samuel S. A Simple Test for Urinary Porphobilinogen. Exp Biol Med. 1941;47(2):393-4

8. Watson CJ. Hematin and Porphyria. N Engl J Med. 1975;293(12):605-7.

9. Watson CJ, Taddeini L, Bossenmaier I. Present Status of the Ehrlich Aldehyde Reaction for Urinary Porphobilinogen. JAMA. 1964;190(6):501-4.

10. Michael B, Corbett MD. The Watson-Schwartz Test. JAMA Intern Med. 1966;195(6):481.

11. Ewing DJ, Campbell IW, Burt AA, et al. Vascular reflexes in diabetic autonomic neuropathy. Lancet. 1973;2(7842):1354-6

12. Ewing DJ, Campbell IW, Murray A, Neilson JM, Clarke BF. Immediate heart-rate response to standing: simple test for autonomic neuropathy in diabetes. BMJ. 1978;1(6106):145-7.

13. Ewing DJ, Clarke BF. Diagnosis and management of diabetic autonomic neuropathy. BMJ. 1982;285(6346):916-8.

14. Bennett T, Farquhar IK, Hosking DJ, Hampton JR. Assessment of methods for estimating autonomic nervous control of the heart in patients with diabetes mellitus. Diabetes. 1978;27(12):1167-74.

15. Levin AB. A simple test of cardiac function based upon the heart rate changes induced by the Valsalva maneuver. Am J Cardiol. 1966;18(1):90-9.

16. Mustajoki $P$, Seppălăinen AM. Neuropathy in latent hereditary hepatic porphyr ia. BMJ. 1975;2(5966):310-2

17. Ewing DJ, Hume L, Campbell IW, et al. Autonomic mechanisms in the initial heart rate response to standing. J Appl Physiol Respir Environ Exerc Physiol. 1980;49(5):809-14.

18. Bhatia SG, Sainani GS, Nayak NJ, Diwate PG. Valsalva manoeuver as a test of autonomic neuropathy in diabetes mellitus. J Assoc Physicians India. 1976;24(2):89-93.

19. Gupta OP, Rastogi DK, Agarwal BL. Cardiovascular reflexes in long-term diabetics. Evaluation by bed side techniques. Indian Heart J. 1978;30(1):10-5.

Cite this article: Ankur, Dilip RM, Askari IH. Assessment of Conventional Autonomic Function Tests in Patients with Acute Intermittent Porphyria. Int J Clin Exp Physiol. 2019;6(4):118-21. 